\title{
Hand hygiene behavior in a tertiary university hospital: differences between surgical and nonsurgical departments
}

\author{
Sendlhofer G. ${ }^{1,2^{*}}$, R. Krause ${ }^{3}$, B. Kober ${ }^{2}$, Vander K. ${ }^{4}$, R. Zierler ${ }^{5}$, G. Brunner ${ }^{6}$, T. Augustin ${ }^{7}$, L. Stelz $\left.\right|^{8}$ and L. P. Kamolz ${ }^{2}$
}

\begin{abstract}
Background: Health care-associated infections are a major patient safety issue worldwide. Hand hygiene $(\mathrm{HH})$ campaigns have started all over the world to increase awareness and decrease HH barriers. The aim of this study was to assess healthcare professionals' $\mathrm{HH}$-knowledge, $\mathrm{HH}$-barriers as well $\mathrm{HH}$-environmental factors in general and especially in surgical and nonsurgical departments within a tertiary university hospital.

Methods: In order to achieve our primary goal, five phases were implemented: i) environmental audit, ii) baseline survey, iii) HH-campaign, iv) follow-up survey and v) alcohol-based hand rub consumption.

Results: The environmental audits showed that $443 \mathrm{HH}$-dispensers were missing. A total of 1,340 questionnaires were returned (baseline: 855; follow-up: 485). Eight HH-barriers were addressed in the baseline survey, 2 of which became significantly reduced during the $\mathrm{HH}$-campaign. $\mathrm{HH}$-environment improved and was followed by a significant increase in compliance with respect to the five moments for $\mathrm{HH}$. Progress in the surgical departments was more evident than in nonsurgical departments. The average procurement of alcohol-based hand rub rose from 105 to $108 \mathrm{~mL}$ per patient day in intensive care units and from 26 to $31 \mathrm{~mL}$ per patient day in wards.

Conclusion: $\mathrm{HH}$-motivation can be addressed with comprehensive $\mathrm{HH}$-campaigns; however, positive role models are needed to attract all healthcare professionals to take part. The necessity of physicians taking part in $\mathrm{HH}$-campaign is the key to the future success of $\mathrm{HH}$-campaigns.
\end{abstract}

Keywords: Hand hygiene, Alcohol-based hand rub, Self-reported adherence

\section{Introduction}

Health care-associated infections (HAI) are a major patient safety issue worldwide. More than 1.4 million people around the world suffer from nosocomial infections and approximately $5-10 \%$ of inpatients in industrialized nations acquire one or more infections in a hospital. For Europe it is estimated that HAIs are responsible for approximately 37,000 deaths annually [1]; in the US, HAIs cause 99,000 deaths per year [2]. This major issue with respect to patient safety has led to numerous hand hygiene $(\mathrm{HH})$ campaigns all over the world, as $\mathrm{HH}$ compliance is still estimated to

\footnotetext{
* Correspondence: gerald.sendlhofer@klinikum-graz.at

'Department of Quality and Risk Management, University Hospital Graz, Graz, Styria, Austria

${ }^{2}$ Division of Plastic, Aesthetic and Reconstructive Surgery, Department of Surgery, Medical University Graz, Graz, Styria, Austria

Full list of author information is available at the end of the article
}

be below $50 \%$ [3-6]. Most healthcare workers are aware of the rationale behind $\mathrm{HH}$-procedures and despite the relative simplicity of $\mathrm{HH}$-procedures, adherence is still unacceptable low [7-9].

Reasons for low adherence are diverse and include environmental barriers such as poor access to $\mathrm{HH}$ products, missing and empty dispensers, or personal barriers such as work overload, stress or simply neglecting to ensure hands are clean [10]. Reasons behind this can lie in limited knowledge of the five moments for $\mathrm{HH}$, a lack of positive role models or simply a lack of interest. So far, barriers to compliance, especially with respect to physician-specific barriers, are poorly understood [11].

Results of $\mathrm{HH}$ campaigns with special focus on bedside hand sanitizing showed sustained improvement in compliance associated with a significant reduction in 
nosocomial infections [12]. In 2009, the University Hospital Graz, a 1,500-bed tertiary university hospital and the second largest in Austria, began implementing comprehensive patient safety tools through the systematic introduction of clinical risk management into routine hospital procedures [13]. In 2012, the Styrian Public Health Fund started the province-wide campaign "Clean Hands" based on an initiative by the Word Health Organization (WHO) and guidelines of the German national $\mathrm{HH}$ campaign to increase healthcare professional awareness of the importance of $\mathrm{HH}$ through alcoholbased hand rub (ABHR). The campaign was implemented within all publicly funded hospitals in Styria and focused on wards and intensive care units. The campaign "Clean Hands" paid attention on improving healthcare professionals' knowledge of the "My 5 Moments for $\mathrm{HH}$ " [14]. The main components of the campaign comprised training, distribution of posters and provision of materials encouraging patients and relatives to clean their hands [15]. Furthermore, the campaign focused on improving environmental barriers, as recent studies have confirmed that $\mathrm{HH}$ compliance can be affected by the accessibility of sanitizing products $[16,17]$.

The aim of this study was to assess healthcare professionals' knowledge of $\mathrm{HH}$-standards before and after the campaign. Secondly, environmental HH-barriers were assessed before and after the campaign. Third, to collect further tips for improvement, the barriers to compliance were analyzed. Finally, the effects of the comprehensive $\mathrm{HH}$-campaign were evaluated with respect to ABHR consumption. Taking the differences between surgical and nonsurgical departments into consideration was part of a post-hoc analysis.

\section{Methods}

The University Hospital consists of 20 departments, of which 16 departments treat inpatients in 13 intensive care units with 135 beds and 58 nursing wards with 1,381 beds. Due to the size of the University Hospital Graz, the rollout of the $\mathrm{HH}$ campaign was carefully planned and implemented over a period of two years to best reach all healthcare professionals. Starting in 2012, 8 departments were included in the campaign (Department of: Dermatology and Venereology, Neurology, Ophthalmology, Orthopedic Surgery, Otorhinolaryngology, Pediatrics and Adolescent Medicine, Pediatrics and Adolescent Surgery, Therapeutic Radiology and Oncology). In 2013 all other departments were added (Department of: Anesthesiology and Intensive Care Medicine, Dentistry and Maxillofacial Surgery, Internal Medicine, Neurosurgery, Obstetrics and Gynecology, Surgery, Trauma Surgery, Urology).

The hand hygiene campaign was divided into following phases within each of the two parts:

\section{Phase 1 - environmental audits}

The identification of environmental barriers included the availability of $\mathrm{HH}$ products in patient room in wards (1 $\mathrm{HH}$-dispenser for two beds) and intensive care units (1 HH-dispenser for one bed) and was audited by hygiene (nurses) experts in May 2012 and April 2013. Thereafter, missing HH-dispensers were optimally placed to best support the workflow. In November 2013 the final audit took place in order to prove, if missing $\mathrm{HH}$ dispensers were placed in the meantime. Each audit lasted approximately between one to two hours for a ward or intensive care unit.

\section{Phase 2 - baseline online survey}

At baseline, before starting the $\mathrm{HH}$ campaign, an online survey assessing subjective $\mathrm{HH}$-environment, $\mathrm{HH}$ barriers and HH-knowledge with respect to the "My 5 Moments for HH" from WHO was conducted. The survey was financed by the Styrian Public Health Fund and was performed by a third party (HEALTH - Institute for Biomedicine and Health Sciences, Joanneum Research Forschungsgesellschaft mbH, Graz, Styria, Austria). The online survey was open to healthcare professionals with an email account. Questions were divided into following sections:

- assessment of the HH-environment (14 questions, see Table 1)

- Assessment of knowledge of the 5 moments for $\mathrm{HH}$ (5 questions, see Table 2)

- Assessment of HH-barriers (8 questions, see Table 3)

Further questions were included in the online survey that will not be part of this publication and contained following sections

- General assessment of the HH-campaign (5 questions)

- Assessment of general knowledge (22 questions)

A letter was sent out in advance informing all healthcare professionals of the $\mathrm{HH}$-campaign as well as measures such as the baseline and follow-up survey. The link to the online survey was sent to all senior department managers by the HEALTH - Institute for Biomedicine and Health Sciences. Healthcare professionals were then invited by their senior managers to participate in the survey and informed about its aims. Additionally, they were told that all data would be stored at the HEALTH - Institute for Biomedicine and Health Sciences and that data analysis would be strictly anonymous. The online survey was open for one month and two reminders were sent to senior managers to increase 
Table 1 Survey results regarding HH-environment. Differences between baseline and follow-up data were assessed by means of Pearson's Chi-Square test total cohort compared to nonsurgical and surgical departments (\%)

\begin{tabular}{|c|c|c|c|c|c|c|c|}
\hline Question & Yes & No & Don't know & \multicolumn{3}{|l|}{ no answer } & $\mathrm{p}$ \\
\hline \multicolumn{8}{|c|}{ Do you think there are enough $\mathrm{HH}$-dispensers? } \\
\hline Baseline & 92.2 & 6.3 & 0.5 & \multicolumn{4}{|l|}{1.1} \\
\hline Follow up & 92.4 & 7.4 & 0.2 & \multicolumn{3}{|l|}{-} & ns \\
\hline Baseline (nonsurgical) & 92.9 & 5.5 & 0.3 & \multicolumn{3}{|l|}{1.3} & \\
\hline Follow up (nonsurgical) & 92.2 & 7.8 & 0.0 & \multicolumn{3}{|l|}{-} & ns \\
\hline Baseline (surgical) & 91.6 & 6.9 & 0.6 & \multicolumn{3}{|l|}{0.8} & \\
\hline Follow up (surgical) & 92.5 & 7.2 & 0.3 & \multicolumn{3}{|l|}{-} & ns \\
\hline \multicolumn{8}{|c|}{ Are there enough possibilities to clean your hands with water and soap? } \\
\hline Baseline & 94.2 & 4.6 & 0.2 & \multicolumn{4}{|l|}{1.1} \\
\hline Follow up & 94.6 & 4.3 & 1.0 & \multicolumn{3}{|l|}{-} & 0.03 \\
\hline Baseline (nonsurgical) & 92.6 & 5.5 & 0.5 & \multicolumn{3}{|l|}{1.3} & \\
\hline Follow up (nonsurgical) & 93.4 & 4.8 & 1.8 & \multicolumn{3}{|l|}{-} & ns \\
\hline Baseline (surgical) & 95.4 & 3.8 & 0.0 & \multicolumn{3}{|l|}{0.8} & \\
\hline Follow up (surgical) & 95.3 & 4.1 & 0.6 & \multicolumn{3}{|l|}{-} & ns \\
\hline \multicolumn{8}{|c|}{ Are there enough $\mathrm{HH}$-products available (hand creme)? } \\
\hline Baseline & 68.4 & 28.7 & 1.9 & \multicolumn{4}{|l|}{1.1} \\
\hline Follow up & 71.3 & 26.6 & 2.1 & \multicolumn{3}{|l|}{-} & ns \\
\hline Baseline (nonsurgical) & 67.5 & 29.8 & 1.3 & \multicolumn{3}{|l|}{1.3} & \\
\hline Follow up (nonsurgical) & 75.4 & 24.0 & 0.6 & \multicolumn{3}{|l|}{-} & ns \\
\hline Baseline (surgical) & 69.1 & 27.7 & 2.3 & \multicolumn{3}{|l|}{0.8} & \\
\hline Follow up (surgical) & 69.2 & 28.0 & 2.8 & \multicolumn{3}{|l|}{-} & ns \\
\hline \multicolumn{8}{|c|}{ Is there an $\mathrm{HH}$-representative in your department? } \\
\hline Baseline & 95.7 & 0.6 & 2.6 & 1.2 & & & \\
\hline Follow up & 96.7 & 0.6 & 2.7 & - & & & ns \\
\hline Baseline (nonsurgical) & 96.3 & 1.3 & 1.1 & 1.3 & & & \\
\hline Follow up (nonsurgical) & 99.4 & 0.0 & 0.6 & - & & & ns \\
\hline Baseline (surgical) & 95.2 & 0.0 & 3.8 & 1.1 & & & \\
\hline Follow up (surgical) & 95.3 & 0.9 & 3.8 & - & & & 0.05 \\
\hline How often HH-dispense & never & every day & once per week & once per month & don't know & No answer & \\
\hline Baseline & 48.8 & 2.9 & 14.9 & 20.6 & 11.8 & 1.1 & \\
\hline Follow up & 39.0 & 4.5 & 19.4 & 22.1 & 15.1 & - & 0.001 \\
\hline Baseline (nonsurgical) & 46.7 & 2.6 & 15.0 & 21.9 & 12.4 & 1.3 & \\
\hline Follow up (nonsurgical) & 41.9 & 4.8 & 25.1 & 17.4 & 10.8 & - & 0.03 \\
\hline Baseline (surgical) & 50.4 & 3.2 & 14.7 & 19.5 & 11.3 & 0.8 & \\
\hline Follow up (surgical) & 37.4 & 4.4 & 16.4 & 24.5 & 17.3 & - & 0.003 \\
\hline & never & sometimes & mostly & always & not available & No answer & \\
\hline Are $\mathrm{HH}$-dispensers near & & & & & & & \\
\hline Baseline & 6.9 & 9.9 & 18.9 & 50.5 & 12.5 & 1.2 & \\
\hline Follow up & 2.3 & 8.2 & 22.1 & 58.1 & 9.3 & - & $<0.001$ \\
\hline Baseline (nonsurgical) & 5.8 & 10.3 & 20.6 & 51.2 & 10.8 & 1.3 & \\
\hline Follow up (nonsurgical) & 3.6 & 8.4 & 21.0 & 49.7 & 17.4 & - & ns \\
\hline Baseline (surgical) & 7.8 & 9.7 & 17.6 & 50.0 & 13.9 & 1.1 & \\
\hline Follow up (surgical) & 1.6 & 8.2 & 22.6 & 62.6 & 5.0 & - & $<0.001$ \\
\hline
\end{tabular}


Table 1 Survey results regarding HH-environment. Differences between baseline and follow-up data were assessed by means of Pearson's Chi-Square test total cohort compared to nonsurgical and surgical departments (\%) (Continued)

\begin{tabular}{|c|c|c|c|c|c|c|c|}
\hline \multicolumn{8}{|c|}{ Are $\mathrm{HH}$-dispensers in the entrance area within the patient room? } \\
\hline Baseline & 3.7 & 4.6 & 11.7 & 67.5 & 11.5 & 1.1 & \\
\hline Follow up & 1.2 & 3.7 & 10.9 & 74.2 & 9.9 & - & 0.009 \\
\hline Baseline (nonsurgical) & 3.7 & 3.2 & 8.4 & 74.4 & 9.0 & 1.3 & \\
\hline Follow up (nonsurgical) & 0.6 & 3.0 & 7.8 & 72.5 & 16.2 & - & 0.038 \\
\hline Baseline (surgical) & 3.8 & 5.7 & 14.3 & 62.0 & 13.4 & 0.8 & \\
\hline Follow up (surgical) & 1.6 & 4.1 & 12.6 & 75.2 & 6.6 & - & 0.001 \\
\hline \multicolumn{8}{|c|}{ Are $\mathrm{HH}$-dispensers anywhere else in the patient room? } \\
\hline Baseline & 7.3 & 12.9 & 13.3 & 44.4 & 20.9 & 1.2 & \\
\hline Follow up & 6.2 & 10.9 & 18.8 & 49.1 & 15.1 & - & 0.001 \\
\hline Baseline (nonsurgical) & 6.9 & 12.4 & 12.4 & 47.2 & 19.8 & 1.3 & \\
\hline Follow up (nonsurgical) & 3.6 & 9.0 & 17.4 & 48.5 & 21.6 & - & ns \\
\hline Baseline (surgical) & 7.6 & 13.2 & 14.1 & 42.2 & 21.8 & 1.1 & \\
\hline Follow up (surgical) & 7.5 & 11.9 & 19.5 & 49.4 & 11.6 & - & 0.001 \\
\hline \multicolumn{8}{|c|}{ Are there $\mathrm{HH}$-dispensers for employees (social room, fitting room)? } \\
\hline Baseline & 3.0 & 7.1 & 15.1 & 69.7 & 3.9 & 1.2 & \\
\hline Follow up & 2.9 & 8.0 & 17.7 & 68.0 & 3.3 & - & ns \\
\hline Baseline (nonsurgical) & 1.3 & 5.0 & 12.4 & 76.8 & 3.2 & 1.3 & \\
\hline Follow up (nonsurgical) & 3.0 & 7.2 & 16.2 & 73.7 & 0.0 & - & 0.041 \\
\hline Baseline (surgical) & 4.4 & 8.8 & 17.2 & 64.1 & 4.4 & 1.1 & \\
\hline Follow up (surgical) & 2.8 & 8.5 & 18.6 & 65.1 & 5.0 & - & ns \\
\hline \multicolumn{8}{|c|}{ Are there $\mathrm{HH}$-dispensers in the consulting room? } \\
\hline Baseline & 0.8 & 0.6 & 8.0 & 81.9 & 7.6 & 1.2 & \\
\hline Follow up & 0.0 & 2.1 & 5.4 & 88.2 & 4.3 & - & $<0.001$ \\
\hline Baseline (nonsurgical) & 0.5 & 0.3 & 7.4 & 86.8 & 3.7 & 1.3 & \\
\hline Follow up (nonsurgical) & 0.0 & 0.6 & 6.0 & 86.2 & 7.2 & - & ns \\
\hline Baseline (surgical) & 1.1 & 0.8 & 8.4 & 77.9 & 10.7 & 1.1 & \\
\hline Follow up (surgical) & 0.0 & 2.8 & 5.0 & 89.3 & 2.8 & - & $<0.001$ \\
\hline \multicolumn{8}{|c|}{ Are there $\mathrm{HH}$-dispensers in public toilets? } \\
\hline Baseline & 0.4 & 1.2 & 7.3 & 81.8 & 8.3 & 1.2 & \\
\hline Follow up & 0.0 & 1.2 & 6.0 & 89.1 & 3.7 & - & 0.001 \\
\hline Baseline (nonsurgical) & 0.8 & 0.8 & 8.2 & 85.2 & 3.7 & 1.3 & \\
\hline Follow up (nonsurgical) & 0.0 & 0.0 & 4.2 & 94.0 & 1.8 & - & ns \\
\hline Baseline (surgical) & 0.0 & 1.5 & 6.5 & 79.0 & 12.0 & 1.1 & \\
\hline Follow up (surgical) & 0.0 & 1.9 & 6.9 & 86.5 & 4.7 & - & 0.003 \\
\hline \multicolumn{8}{|c|}{ Are there $\mathrm{HH}$-dispensers in staff lavatory? } \\
\hline Baseline & 0.1 & 0.4 & 3.3 & 94.3 & 0.8 & 1.2 & \\
\hline Follow up & 0.2 & 0.6 & 4.1 & 94.0 & 1.0 & - & ns \\
\hline Baseline (nonsurgical) & 0.3 & 0.0 & 3.7 & 94.2 & 0.5 & 1.3 & \\
\hline Follow up (nonsurgical) & 0.0 & 0.6 & 3.0 & 96.4 & 0.0 & - & ns \\
\hline Baseline (surgical) & 0.0 & 0.6 & 2.9 & 94.3 & 1.1 & 1.1 & \\
\hline Follow up (surgical) & 0.3 & 0.6 & 4.7 & 92.8 & 1.6 & - & ns \\
\hline
\end{tabular}


Table 1 Survey results regarding HH-environment. Differences between baseline and follow-up data were assessed by means of Pearson's Chi-Square test total cohort compared to nonsurgical and surgical departments (\%) (Continued)

\begin{tabular}{|c|c|c|c|c|c|c|c|}
\hline \multicolumn{8}{|c|}{ Are there portable HH-dispensers (i.e., ward round trolley)? } \\
\hline Baseline & 6.5 & 5.7 & 9.8 & 57.9 & 18.8 & 1.2 & \\
\hline Follow up & 1.6 & 2.9 & 10.5 & 69.7 & 15.3 & - & $<0.001$ \\
\hline Baseline (nonsurgical) & 6.1 & 5.8 & 9.2 & 59.4 & 18.2 & 1.3 & \\
\hline Follow up (nonsurgical) & 1.8 & 3.0 & 8.4 & 56.9 & 29.9 & - & 0.007 \\
\hline Baseline (surgical) & 6.9 & 5.7 & 10.3 & 56.7 & 19.3 & 1.1 & \\
\hline Follow up (surgical) & 1.6 & 2.8 & 11.6 & 76.4 & 7.5 & - & $<0.001$ \\
\hline \multicolumn{8}{|c|}{ Do you use pocket-sized bottles for $\mathrm{HH}$ ? } \\
\hline Baseline & 64.9 & 2.8 & 1.1 & 1.5 & 28.3 & 1.4 & \\
\hline Follow up & 59.0 & 2.3 & 1.4 & 4.3 & 33.0 & - & 0.001 \\
\hline Baseline (nonsurgical) & 65.2 & 3.2 & 1.3 & 1.3 & 27.7 & 1.3 & \\
\hline Follow up (nonsurgical) & 55.7 & 1.8 & 1.8 & 1.8 & 38.9 & - & ns \\
\hline Baseline (surgical) & 64.7 & 2.5 & 0.8 & 1.7 & 28.8 & 1.5 & \\
\hline Follow up (surgical) & 60.7 & 2.5 & 1.3 & 5.7 & 29.9 & - & 0.011 \\
\hline
\end{tabular}

participation. Healthcare professionals had the option to decline participation or to withdraw from the survey at any time. Participants were also allowed to skip questions if they felt uncomfortable answering them. The online survey was approved by the Management Board of the Medical University Graz and University Hospital Graz. The HH-campaign was approved by the Medical University Graz Ethics Committee (vote-number: 27-233 ex 14/15).

\section{Phase 3 - HH-campaign}

Healthcare professionals were informed about the aim and scope of the $\mathrm{HH}$ campaign by hygiene experts. In each ward or intensive care unit, an introduction to the "My 5 Moments for $\mathrm{HH}$ " was given. Healthcare professionals were also provided face-to-face trainings by hygiene experts and were given the opportunity to use media resources (movie from Charité Berlin, Germany). Posters were strategically located in wards and intensive care units and leaflets were given to healthcare professionals and patients. All training sessions were documented. Finally, $\mathrm{HH}$ topics were promoted via an electronic newsletter, via the hospital newspaper and regular in-house conferences organized by the Department of Quality and Risk Management.

\section{Phase 4 - follow up online survey}

After implementing the $\mathrm{HH}$ campaign, a follow-up online survey was conducted using the analog procedure as described in phase 2 .

\section{Phase 5 - alcohol-based hand rub consumption}

AHBR was assessed for 2011 and monitored for 2012 and 2013. Data were documented in the "National Reference Centre for the Surveillance of Nosocomial Infections",
Germany. Results of AHBR usage were continuously reported to all executive managers of the respective departments.

\section{Statistical analysis}

Data of the online survey were collected by HEALTH Institute for Biomedicine and Health Sciences, Joanneum Research Forschungsgesellschaft $\mathrm{mbH}$, Graz, Styria, Austria. Survey data were analyzed using descriptive statistics. Differences between baseline and followup data were assessed by means of Pearson's Chi-Square test. All analyses were conducted using R 2.13.1.

\section{Results}

\section{Environmental audits}

Environmental baseline audits showed that $842 \mathrm{HH}$ dispensers on wards and intensive care units were in place, whereas the evaluated target goal of $\mathrm{HH}$ dispensers which came apparent during the audits was 1,285. New $\mathrm{HH}$ dispensers were immediately ordered to replace missing ones. In 2013, a third audit revealed that almost all $\mathrm{HH}$ dispensers had been fixed, however, 60 remained missing. In case of missing $\mathrm{HH}$ dispensers, healthcare professionals received pocket-sized bottles.

\section{Survey participation}

General participant demographics are outlined in Table 4. Healthcare professionals (physicians: $n=1072$; nurses: $n=$ 2700; others: $n=357$ ) were asked to participate in the baseline online survey and a total of 855 (20.7 \%) took part in the baseline survey. The follow-up survey was answered by 485 healthcare professionals $(12.0 \%)$. The return rate among physicians was low (9.4\% baseline versus $4.1 \%$ follow-up), followed by a moderate return rate for nurses ( $21.6 \%$ baseline versus $11.8 \%$ follow up) and was high for 
Table 2 Survey results regarding the behavior with respect to the "My 5 Moments for HH", total cohort compared to nonsurgical and surgical departments (\%)

\begin{tabular}{|c|c|c|c|c|c|c|}
\hline \multirow[t]{2}{*}{ Question } & \multicolumn{5}{|c|}{ Answers } & \multirow[t]{2}{*}{$\mathrm{p}$} \\
\hline & always & very often & sometimes & never & n.a. & \\
\hline \multicolumn{7}{|c|}{ Do you clean your hands before patient contact? } \\
\hline Baseline & 63.6 & 27.5 & 6.0 & 0.6 & 2.3 & \\
\hline Follow up & 74.4 & 20.6 & 4.5 & 0.4 & - & $<0.001$ \\
\hline Baseline (nonsurgical) & 63.1 & 27.7 & 6.3 & 0.8 & 2.1 & \\
\hline Follow up (nonsurgical) & 71.9 & 23.4 & 4.8 & 0.0 & - & ns \\
\hline Baseline (surgical) & 64.1 & 27.3 & 5.7 & 0.4 & 2.5 & \\
\hline Follow up (surgical) & 75.8 & 19.2 & 4.4 & 0.6 & - & 0.001 \\
\hline \multicolumn{7}{|c|}{ Do you clean your hands before aseptic task? } \\
\hline Baseline & 80.6 & 12.2 & 3.4 & 1.5 & 2.3 & \\
\hline Follow up & 85.8 & 9.3 & 2.7 & 2.3 & - & 0.003 \\
\hline Baseline (nonsurgical) & 79.9 & 12.7 & 3.7 & 1.6 & 2.1 & \\
\hline Follow up (nonsurgical) & 82.6 & 13.2 & 4.2 & 0.0 & - & ns \\
\hline Baseline (surgical) & 81.1 & 11.8 & 3.2 & 1.5 & 2.5 & \\
\hline Follow up (surgical) & 87.4 & 7.2 & 1.9 & 3.5 & - & 0.002 \\
\hline \multicolumn{7}{|c|}{ Do you clean your hands after body fluid exposure risk? } \\
\hline Baseline & 95.3 & 1.9 & 0.2 & 0.2 & 2.3 & \\
\hline Follow up & 97.9 & 1.0 & 0.2 & 0.8 & - & $<0.001$ \\
\hline Baseline (nonsurgical) & 94.2 & 2.9 & 0.5 & 0.3 & 2.1 & \\
\hline Follow up (nonsurgical) & 97.6 & 1.8 & 0.6 & 0.0 & - & ns \\
\hline Baseline (surgical) & 96.2 & 1.1 & 0.0 & 0.2 & 2.5 & \\
\hline Follow up (surgical) & 98.1 & 0.6 & 0.0 & 1.3 & - & 0.008 \\
\hline \multicolumn{7}{|c|}{ Do you clean your hands after patient contact? } \\
\hline Baseline & 81.1 & 14.2 & 2.3 & 0.1 & 2.3 & \\
\hline Follow up & 86.8 & 12.2 & 0.6 & 0.4 & - & $<0.001$ \\
\hline Baseline (nonsurgical) & 81.0 & 14.0 & 2.6 & 0.3 & 2.1 & \\
\hline Follow up (nonsurgical) & 87.4 & 12.0 & 0.6 & 0.0 & - & ns \\
\hline Baseline (surgical) & 81.1 & 14.3 & 2.1 & 0.0 & 2.5 & \\
\hline Follow up (surgical) & 86.5 & 12.3 & 0.6 & 0.6 & - & 0.005 \\
\hline \multicolumn{7}{|c|}{ Do you clean your hands after contact with patient surroundings? } \\
\hline Baseline & 36.1 & 35.3 & 23.2 & 3.0 & 2.3 & \\
\hline Follow up & 48.9 & 34.0 & 14.6 & 2.5 & - & $<0.001$ \\
\hline Baseline (nonsurgical) & 36.4 & 35.6 & 23.2 & 2.6 & 2.1 & \\
\hline Follow up (nonsurgical) & 47.3 & 34.1 & 16.2 & 2.4 & - & 0.044 \\
\hline Baseline (surgical) & 35.9 & 35.1 & 23.1 & 3.4 & 2.5 & \\
\hline Follow up (surgical) & 49.7 & 34.0 & 13.8 & 2.5 & - & $<0.001$ \\
\hline
\end{tabular}

the other group (48.2\% baseline versus $34.2 \%$ follow up), i.e., medical technical assistants.

A total of 379 employees from nonsurgical departments participated in the baseline survey, and a total of 167 employees in the follow-up survey. The distribution of respondents was as follows: Department of Internal Medicine, 179 (47.2\%) versus 20 (11.9\%), Department of Pediatrics and Adolescent Medicine, 79 (20.8\%) versus 56 (33.5\%), Department of Neurology, 76 (20.1\%) versus 78 (46.7\%), Department of Therapeutic Radiology and Oncology, 13 (3.4\%) versus 6 (3.6\%). $8.5 \%$ provided no information.

A total of 476 employees from surgical departments participated in the baseline survey, and a total of 318 employees in the follow-up survey. The distribution of respondents was as follows: Department of Surgery, 
Table 3 Barriers not to clean their hands (\%), total cohort compared to nonsurgical and surgical departments (\%)

\begin{tabular}{|c|c|c|c|}
\hline Reason & Baseline & Follow up & $p$ \\
\hline 1) Not enough time & 12.40 & 13.61 & ns \\
\hline nonsurgical & 11.61 & 9.58 & ns \\
\hline surgical & 13.03 & 15.72 & ns \\
\hline 2) $\mathrm{HH}$-dispenser was missing & 5.38 & 5.15 & ns \\
\hline nonsurgical & 5.28 & 3.59 & ns \\
\hline surgical & 5.46 & 5.97 & ns \\
\hline $\begin{array}{l}\text { 3) } \mathrm{HH} \text {-dispenser was not on } \\
\text { the right place }\end{array}$ & 7.95 & 5.77 & ns \\
\hline nonsurgical & 6.86 & 4.79 & ns \\
\hline surgical & 8.82 & 6.29 & ns \\
\hline 4) $\mathrm{HH}$ is irritating the skin & 2.22 & 2.27 & ns \\
\hline nonsurgical & 2.37 & 3.59 & ns \\
\hline surgical & 2.10 & 1.57 & ns \\
\hline 5) Forgotten & 15.32 & 16.08 & ns \\
\hline nonsurgical & 15.30 & 16.77 & ns \\
\hline surgical & 15.34 & 15.72 & ns \\
\hline 6) I use hand gloves & 27.37 & 17.94 & $<0.001$ \\
\hline nonsurgical & 27.70 & 20.36 & ns \\
\hline surgical & 27.10 & 16.67 & 0.001 \\
\hline 7) There is no reason for $\mathrm{HH} /$ no risk & 23.39 & 21.24 & ns \\
\hline nonsurgical & 24.54 & 23.95 & ns \\
\hline surgical & 22.48 & 19.81 & ns \\
\hline 8) Emergency case & 34.04 & 25.57 & 0.002 \\
\hline nonsurgical & 37.20 & 29.94 & ns \\
\hline surgical & 31.51 & 23.27 & 0.014 \\
\hline
\end{tabular}

\section{Assessment of $\mathrm{HH}$ barriers}

Healthcare professionals ranked $8 \mathrm{HH}$ barriers. The overall self-reported rate of barriers to hand cleaning

Table 4 Participation of healthcare professionals for the baseline and follow-up online survey

\begin{tabular}{|c|c|c|c|c|c|c|}
\hline \multirow[b]{2}{*}{ Participants (n) } & \multicolumn{3}{|l|}{ Baseline } & \multicolumn{3}{|l|}{ Follow up } \\
\hline & $\begin{array}{l}\text { Total } \\
855(100 \%)\end{array}$ & $\begin{array}{l}\text { nonsurgical } \\
379(44.3 \%)\end{array}$ & $\begin{array}{l}\text { surgical } \\
476(55.7 \%)\end{array}$ & $\begin{array}{l}\text { Total } \\
485 \text { (100\%) }\end{array}$ & $\begin{array}{l}\text { nonsurgical } \\
167(34.4 \%)\end{array}$ & $\begin{array}{l}\text { surgical } \\
318(65.6 \%)\end{array}$ \\
\hline Physician & $101(11.8 \%)$ & $23(6.1 \%)$ & $78(16.4 \%)$ & $44(9.1 \%)$ & $6(3.6 \%)$ & $38(11.9 \%)$ \\
\hline Nurses & $582(68.1 \%)$ & $279(73.6 \%)$ & $303(63.7 \%)$ & $319(65.8 \%)$ & $119(71.3 \%)$ & $200(62.9 \%)$ \\
\hline Others & $172(20.1 \%)$ & $77(20.3 \%)$ & $95(19.9 \%)$ & $122(25.1 \%)$ & $42(25.1 \%)$ & $80(25.2 \%)$ \\
\hline Female & $724(84.7 \%)$ & $314(82.8 \%)$ & $410(86.1 \%)$ & $425(87.6 \%)$ & $153(91.6 \%)$ & $272(85.5 \%)$ \\
\hline Male & $131(15.3 \%)$ & $65(17.2 \%)$ & $66(13.9 \%)$ & $60(12.4 \%)$ & $14(8.4 \%)$ & $46(14.5 \%)$ \\
\hline Employed $<1$ year & $47(5.5 \%)$ & $25(6.6 \%)$ & $22(4.6 \%)$ & $18(3.7 \%)$ & $6(3.6 \%)$ & $12(3.8 \%)$ \\
\hline Employed 1 to 2 years & 85 (9.9\%) & $39(10.3 \%)$ & $46(9.7 \%)$ & $33(6.8 \%)$ & $11(6.6 \%)$ & $22(6.9 \%)$ \\
\hline Employed 3 to 5 years & $98(11.5 \%)$ & $46(12.1 \%)$ & $52(10.9 \%)$ & $69(14.2 \%)$ & $28(16.8 \%)$ & $41(12.9 \%)$ \\
\hline Employed 6 to 10 years & $146(17.1 \%)$ & $56(14.8 \%)$ & $90(18.9 \%)$ & $78(16.1 \%)$ & $22(13.2 \%)$ & $56(17.6 \%)$ \\
\hline Employed 11 to 20 years & $201(23.5 \%)$ & $99(26.1 \%)$ & $102(21.4 \%)$ & $116(23.9 \%)$ & $51(30.5 \%)$ & $65(20.4 \%)$ \\
\hline Employed $>20$ years & $278(32.5 \%)$ & $114(30.1 \%)$ & $164(34.5 \%)$ & $171(35.3 \%)$ & $49(29.3 \%)$ & $122(38.4 \%)$ \\
\hline
\end{tabular}


showed improvements in two of these barriers (Table 3). Significant improvement was achieved only in surgical departments.

\section{Alcohol-based hand rub consumption}

The average use of ABHR increased over time from 105 to $108 \mathrm{~mL}$ per patient bed day in intensive care units and from 26 to $31 \mathrm{~mL}$ per patient bed day in wards (Table 5), and was similar when compared to centers of reference (ns).

\section{Discussion}

$\mathrm{HH}$ is considered to be the most important measure to prevent nosocomial infections [5], therefore the WHO started a global campaign to ensure that infection control is acknowledged universally [14]. As suggested by Erasmus, the first step toward developing interventions should be to identify the prevalence of risk behavior, such as non-compliance [5]. Previously, multiple studies were undertaken to identify barriers [18] and within our $\mathrm{HH}$ campaign 8 barriers were ranked. The top five reasons for non-hand washing were: i) an emergency case, ii) the use of gloves, iii) no reason to clean the hands, iv) forgetting and finally v) not enough time. In promoting the $\mathrm{HH}$ campaign for three years, only two of the top five barriers improved within surgical departments. For diverse reasons, five departments were underrepresented in the online survey; however, the study provides insights into and gives tips for the necessity of senior managers at all levels to support the $\mathrm{HH}$ campaign in order to achieve a cultural change. Hugonnet and Perneger [19] explain that attitude towards and compliance with $\mathrm{HH}$ is behavioral in essence and that there is a need to enhance role modeling by superiors as prerequisite for the future success.

A plethora of strategies and interventions to best improve $\mathrm{HH}$ compliance have been described in the literature, and can be summarized into six categories, i) resources, ii) staff education and training, iii) prompts or reminders, iv) monitoring and feedback, v) cultural and organizational changes and vi) campaigns [20]. We focused on all of the above-mentioned categories in order to reach our goal of addressing the necessity of $\mathrm{HH}$. The first bundle within the HH-campaign in Styria and within the University Hospital Graz had been certain organizational changes. The Styrian Public Health Fund connected procedure-oriented hospital financing based on diagnosis related groups for public funded hospitals to the HH-campaign. Secondly, much emphasis was put onto improving the $\mathrm{HH}$ environment and new $\mathrm{HH}$ dispensers were added according to the results of the environmental audits. Although it was remarkable that more than $400 \mathrm{HH}$ dispensers were missing within the University Hospital prior the initiation of the $\mathrm{HH}$-campaign, they were optimally placed thereafter within a reasonable time. In some cases employees received pocketsized bottles. Environmental audits were very encouraging, as the results of the follow-up audit and the survey showed overall improvements, specifically in surgical departments.

A number of factors affected compliance and were associated with differences in compliance rates between physicians and nurses [5]. The overall participation of physicians in these two surveys was very low, good for nurses and very high for others. The analysis of the survey ensured that the results did not distinguish between professional groups. It is well known that physicians respond less often to surveys and seem to assign less importance to $\mathrm{HH}$ in general [21]. However, we believe that in order to attain some type of safety culture, we have to evoke positive rather than negative associations with $\mathrm{HH}$.

The Joint Commission, which expected hospitals to achieve $>90 \%$ compliance, found that many hospitals

Table 5 Alcohol-based hand rub consumption over three years (baseline: 2011; follow up period 2012 and 2013) in intensive care units $^{1}$ and wards of the University Hospital Graz ${ }^{1}$ compared with reference centers ${ }^{2}$ in Germany, Switzerland and Austria

\begin{tabular}{|c|c|c|c|c|c|c|c|c|c|c|c|}
\hline & \multirow{2}{*}{$\begin{array}{l}\text { Patient } \\
\text { days } \\
\text { (PD) }\end{array}$} & \multirow{2}{*}{$\begin{array}{l}\text { Yearly } \\
\text { consumption } \\
\text { Of } \mathrm{HH} \text { in L }\end{array}$} & \multirow[t]{2}{*}{$\begin{array}{l}\text { Consumption } \\
\mathrm{HH} \text { in } \mathrm{ml} / \mathrm{PD}\end{array}$} & \multirow{2}{*}{$\begin{array}{l}\text { Mean } \\
\text { number of } \\
\mathrm{HH} \mathrm{PD}^{1}\end{array}$} & \multicolumn{6}{|c|}{$\begin{array}{l}\text { Reference centers } \\
\text { consumption }\end{array}$} & \multirow{2}{*}{$\begin{array}{l}\text { Mean } \\
\text { number } \\
\mathrm{HH} / \mathrm{PD}^{2}\end{array}$} \\
\hline & & & & & Mean & *P10 & P25 & P50 & P75 & P90 & \\
\hline \multicolumn{12}{|c|}{ Intensive Care Units } \\
\hline 2011 & 43.610 & 4.595 & 105 & 35 & 95 & 51 & 68 & 88 & 111 & 146 & 32 \\
\hline 2012 & 50.024 & 5.043 & 101 & 34 & 104 & 57 & 73 & 95 & 123 & 159 & 35 \\
\hline 2013 & 51.152 & 5.528 & 108 & 36 & 109 & 57 & 75 & 98 & 127 & 167 & 36 \\
\hline \multicolumn{12}{|c|}{ Words } \\
\hline 2011 & 360.505 & 9.541 & 26 & 9 & 23 & 11 & 15 & 21 & 28 & 40 & 8 \\
\hline 2012 & 360.866 & 10.186 & 28 & 9 & 24 & 12 & 17 & 22 & 30 & 43 & 8 \\
\hline 2013 & 356.250 & 10.950 & 31 & 10 & 25 & 13 & 17 & 23 & 32 & 45 & 8 \\
\hline
\end{tabular}


did not achieve the goal [22]. Our study did not measure actual adherence to $\mathrm{HH}$ practices, however, according to the self-reported adherence which was assessed during the baseline and follow-up survey, results show improvements with respect to the knowledge to the "My 5 Moments for HH". For indications 1 and 2 (Table 2), improvements were achieved. For indications 3 and 4, the already good results improved, too. This can be explained as practices that reflect a ritualized behavior mainly for self-protection against infection $[8,21]$. For indication 5, a remarkable improvement was achieved; however, the need to clean hands after coming into contact with surfaces in the patient area in general was very low both before and after the campaign. Still, we have to work on increasing acceptance and further enhancing knowledge of the five moments for $\mathrm{HH}$.

Using direct observation to assess $\mathrm{HH}$ compliance is considered to be the norm when measuring compliance and is the gold standard [5, 6, 22]; however, it remains unclear how valid the method is as an indicator of adherence to $\mathrm{HH}$ guidelines [5]. Apart from direct observation, ABHR-consumption is a further indicator of $\mathrm{HH}$ compliance [5]. Therefore, accessibility of $\mathrm{HH}$ dispensers was a prerequisite to improve in $\mathrm{HH}$. ABHR-consumption per patient-day slightly increased in wards and intensive care units over the recent years. We assume that this is not only linked to improved $\mathrm{HH}$ infrastructure, it shows that staff education and training throughout the campaign was good.

Overall, the study highlighted the need to improve participation of all healthcare professionals in the campaign; generally physicians and especially within this professional group, physicians working in nonsurgical departments were underrepresented in the survey. The majority of healthcare professionals have long and valuable experience, but at the individual level, strengthening a positive attitude towards hand hygiene is needed [7].

The HH-campaign and the survey have several limitations. There was no control group despite having compared behavior before and after the campaign. Another limitation of the current study was the poor response rate to the survey. Poor participation was probably influenced by conducting other surveys within a short period of time. Additionally, the response rate was probably linked to the fact that the survey was sent out by senior managers of corresponding departments. Some might have neglected to send out the email to their employees or some might have just sent out the link to some but not all employees within a department. Another reason for the poor response rate could have been the peculiar fact that 25- $50 \%$ of all employees within our hospital had not yet activated their email account, which was discovered after another survey was performed [23]. Finally, the study lacks information on whether training was inadequate and therefore might have influenced outcome measures.

\section{Conclusion}

$\mathrm{HH}$ motivation can be addressed with comprehensive $\mathrm{HH}$ campaigns; however, positive role models are needed to attract all healthcare professionals to participate. Selfprotection is the strongest predictor and increased within our campaign. An improved $\mathrm{HH}$ environment supported the use of ABHR and consumption per patient-day slightly increased over time. Still, there is much to learn about the behavior of healthcare professionals with respect to $\mathrm{HH}$ barriers in order to improve in the near future.

\section{Competing interests}

The authors have no competing interests.

\section{Acknowledgements}

The authors wish to express their gratitude to the Styrian Public Health Fund for the initiation and financing of the province wide $\mathrm{HH}$-campaign. For performing the environmental audits as well as $\mathrm{HH}$-trainings we would like to thank the hygiene-nursing team H. Hörhan, C. Jeuschnigger, K. Pepper, Ch. Prietl as well as in the meantime the retired Head of the Institute for Hospital Hygiene and Microbiology A. Bogiatzis. Furthermore, we would like to thank the entire organization and their employees for supporting the $\mathrm{HH}$ campaign. We also would like to thank "National Reference Centre for the Surveillance of Nosocomial Infections" (www.nrz-hygiene.de) for surveillance data with respect to $\mathrm{HH}$-consumption.

\section{Funding}

There was no funding.

\section{Author details}

'Department of Quality and Risk Management, University Hospital Graz, Graz, Styria, Austria. ${ }^{2}$ Division of Plastic, Aesthetic and Reconstructive Surgery, Department of Surgery, Medical University Graz, Graz, Styria, Austria. ${ }^{3}$ Department of Internal Medicine, Section of Infectious Diseases and Tropical Medicine, Medical University Graz, Graz, Styria, Austria. ${ }^{4}$ Institute for Hospital Hygiene and Microbiology, KAGes, Styria, Austria. ${ }^{5}$ Department of Paediatric and Adolescent Surgery, University Hospital Graz, Graz, Styria, Austria. ${ }^{6}$ University Hospital Graz, Graz, Styria, Austria. ${ }^{7} \mathrm{HEALTH}$ - Institute for Biomedicine and Health Sciences, Joanneum Research,

Forschungsgesellschaft mbH, Graz, Styria, Austria. ${ }^{8}$ Styrian Public Health Fund, Graz, Austria.

Received: 24 March 2015 Accepted: 30 April 2015

Published online: 10 August 2015

\section{References}

1. Exploring patient participation in reducing health-care-related safety risks. Word Health Organization, Europe, 2013: ISBN:978-92-890-0294-3

2. Klevens RM, Edwards JR, Richards CL, et al. Estimating health care-associated infections and deaths in U.S. hospitals, 2002. Public Health Rep. 2007;122:160.166.

3. Pittet D, Mourouge P, Perneger TV, et al. Compliance with handwashing in a teaching hospital. Ann Intern Med. 1999;130:126-30.

4. Aboumatar H, Ristaino P, Davis RO, et al. Infection prevention promotion based on the PRECEDE model: improving hand hygiene behaviors among healthcare personnel. Infect Control Hosp Epidemiol. 2012;33:144-51.

5. Erasmus V, Daha TJ, Brug H. Systematic review of studies on compliance with hand hygiene guidelines in hospital care. Infect Control Hosp Epidemiol. 2010;31:283-94.

6. Srigley JA, Furness CD, Baker GR, Gardam M. Quantification of the Hawthorne effect in hand hygiene compliance monitoring using an electronic monitoring system: a retrospectve cohort study. BMJ Qual Saf. 2014;23:974-80. 
7. Pittet $D$, Simon A, Hugonnet S, Pessoa-Silva CL, Sauvan V, Perneger TV. Hand hygiene among physicians: performance, beliefs, and perceptions. Ann Intern Med. 2004;141(1):1-8. doi:10.7326/0003-4819-141-1-200407060-00008.

8. Whitby M, McLaws ML, Ross MW. Why healthcare workers don't wash their hands: a behavioral explanation. Infec Control Hosp Epidemiol. 2006;27:484-92

9. O'Boyle CA, Henly SJ, Larson E. Understanding adherence to hand hygiene recommendations: the theory of planned behavior. Am J Infect Control. 2001;29(6):352-60.

10. Boyce JM, Pittet D. Healthcare infection control practices advisory committee; HICPAC/SHEA/APIC/IDSA hand hygiene task force. Guideline for hand hygiene in health-care settings. Recommendations of the healthcare infection control practices advisory committee and the HICPAC/SHEA/APIC/ IDSA hand hygiene task force. Am J Infect Control. 2002;30:S1-46.

11. Squires JE, Suh KN, Linklater $\mathrm{S}$, et al. Improving physician hand hygiene compliance using behavioural theories: a study protocol. Implement Sci. 2013;8:16. doi:10.1186/1748-5908-8-16.

12. Pittet $\mathrm{D}$, Hugonnet $\mathrm{S}$, Harbart $\mathrm{S}$, et al. Effectiveness of a hospital-wide programme to improve compliance with hand hygiene. Lancet. 2000;356:1307-12.

13. Sendlhofer G, Brunner G, Tax Ch, Falzberger G, Smolle J, et al. (2015) Systematic implementation of clinical risk management in a large university hospital: the impact of risk managers. Wien Klin Wochenschrift 2015;127:1-11 doi: 10.1007/s00508-014-0620-7

14. World Health Organization. Patient Safety. WHO Guidelines on Hand Hygiene in Health Care. First global patient safety challenge clean care is safer care. 2009; http://www.who.int/gpsc/5may/en/ (accessed 15 May 2014)

15. Stone SP, Fuller C, Savage J, Cooksan B, Hayward A, Cooper B, et al. Evaluation of the national cleanyourhands campaign to reduce Staphylococcus aureus bacteraemia and clostridium difficile infection in hospitals in England and Wales by improved hand hygiene; four year, prospective, ecological, interrupted time series study. BMJ. 2012;344, e3005. doi:10.1136/bmj.e3005 (published 3 May 2012).

16. Chan BP, Homa K, Kirkland KB. Effect of varying the number and location of alcohol-based hand rub dispensers on usage in a general inpatient medical unit. Infect Control Hosp Epidemiol. 2013;34:987-9.

17. Cure L, Van Enk R, Tiong E. A systematic approach for the location of hand sanitizer dispensers in hospitals. Health Care Manag Sci. 2014;17(3):245-58. doi:10.1007/s10729-013-9254-y.

18. Park JH, Cheong HK, Son DY, Kim SU, Chang-Min H. Perceptions and behaviors related to hand hygiene for the prevention of $\mathrm{H} 1 \mathrm{~N} 1$ influenza transmission among Korean university students during the peak pandemic period. BMC Infectious Diseases 2010;10:222

19. Hugonnet S, Perneger TV, Pittet D. Alcohol-based handrub improves compliance with hand hygiene in intensive care units. Arch Intern Med. 2002;162:1037-43.

20. McInnes E, Phillips R, Middleton S, Gould D. A qualitative study of senior hospital managers' views on current and innovative strategies to improve hand hygiene. BMC Infect Dis. 2014;14:611.

21. Sax H, Uckay I, Richet H, Allegranzi B, Pittet D. Determinants of good adherence to hand hygiene among healthcare workers who have extensive exposure to hand hygiene campaign. Inf Control Hosp Epid. 2007;28(11):1267-74.

22. Boyce JM. Update on hand hygiene. American J Infection Control. 2013;41:S94-6.

23. Sendlhofer G, Mosbacher N, Leitgeb K, Kober B, Jantscher L, Berghold A, et al. Implementation of a surgical safety checklist: interventions to optimize the process and hints to increase compliance. PLoS One. 2015;10(2) e0116926. doi:10.1371/journal.pone.0116926.

\section{Submit your next manuscript to BioMed Central and take full advantage of:}

- Convenient online submission

- Thorough peer review

- No space constraints or color figure charges

- Immediate publication on acceptance

- Inclusion in PubMed, CAS, Scopus and Google Scholar

- Research which is freely available for redistribution

Submit your manuscript at www.biomedcentral.com/submit 